ABSTRACT: To determine normative values for nerve conduction studies among workers, we selected a subset of 326 workers from 955 subjects who participated in medical surveys in the workplace. The reference cohort was composed exclusively of active workers, in contrast to the typical convenience samples. Nerve conduction measures included bilateral median and ulnar sensory amplitude and latency (onset and peak). Workers with upper extremity symptoms, medical conditions that could adversely affect peripheral nerve function, low hand temperature, or highly repetitive jobs were excluded from the "normal" cohort. Linear regression models explained between $21 \%$ and $51 \%$ of the variance in nerve function, with covariates of age, sex, hand temperature, and anthropometric factors. The most robust models were fitted for sensory amplitudes in the median and ulnar nerves for dominant and nondominant hands. The median-ulnar difference was least sensitive to adjustment, indicating it is the best measure to use if corrections are not made to account for relevant covariates. A key point was that the magnitude of variance increased with age and anthropometric factors. These findings provide strong evidence that to improve diagnostic accuracy, electrodiagnostic testing should control for relevant covariates, particularly age, sex, hand temperature, and anthropometric factors.

(C) 1998 John Wiley \& Sons, Inc. Muscle Nerve 21: 999-1005, 1998

\title{
MEDIAN AND ULNAR NERVE CONDUCTION STUDIES AMONG WORKERS: NORMATIVE VALUES
}

\author{
DEBORAH F. SALERNO, MS, ${ }^{1}$ ALFRED FRANZBLAU, MD, ${ }^{1,2}$ \\ ROBERT A. WERNER, MD, ${ }^{1,2,3,4}$ MARK B. BROMBERG, MD, PhD, ${ }^{5}$ \\ THOMAS J. ARMSTRONG, PhD, ${ }^{1,2}$ and JAMES W. ALBERS, MD, PhD ${ }^{1,6}$ \\ ${ }^{1}$ Department of Environmental and Industrial Health, School of Public Health, The \\ University of Michigan, 1420 Washington Heights, \\ Ann Arbor, Michigan 48109-2029, USA \\ ${ }^{2}$ Center for Ergonomics, School of Engineering, The University of Michigan, \\ Ann Arbor, Michigan, USA \\ ${ }^{3}$ Physical Medicine and Rehabilitation, Ann Arbor Veterans Administration \\ Hospital, Ann Arbor, Michigan, USA \\ ${ }^{4}$ Department of Physical Medicine and Rehabilitation, School of Medicine, The \\ University of Michigan, Ann Arbor, Michigan, USA \\ ${ }^{5}$ Department of Neurology, School of Medicine, The University of Utah, \\ Salt Lake City, Utah, USA \\ ${ }^{6}$ Department of Neurology, The University of Michigan Medical Center, \\ Ann Arbor, Michigan, USA
}

Received 17 September 1997; accepted 10 January 1998

Nerve conduction studies (NCS) are commonly used in the diagnosis of peripheral nerve disorders, and results are routinely compared to normative values to discern abnormalities. For this reason, proper comparison values are critical for valid interpretation. Recently, there has been increased attention to the quality of normative data against which test re-

Key words: carpal tunnel syndrome; median nerve; nerve conduction studies; normative values; occupational disease; ulnar nerve Correspondence to: Dr. Alfred Franzblau

CCC 0148-639X/98/080999-07

(C) 1998 John Wiley \& Sons, Inc sults are compared. ${ }^{8}$ We investigated how the electrophysiological definition of "normal" affects the confirmation of diagnosis of carpal tunnel syndrome (CTS) among workers, since active workers may impose special requirements on how normative data are used. This report focuses on the evaluation of NCS for upper extremity mononeuropathies and CTS, particularly among workers.

A distinctive feature of this investigation is that our reference cohort was well defined and composed exclusively of active workers, in contrast to the typical convenience samples of patients in a hospital 
or clinic. The "normal" cohort was selected from the larger worker population under surveillance. In addition, as recommended in discussions of reference values ${ }^{20}$ and interpretation of electrodiagnostic findings, ${ }^{2,23,27,31}$ we present models exploring the relationship of sensory nerve function to age, sex, hand temperature, and anthropometric factors.

\section{NORMATIVE VALUE DETERMINATION}

A normal range may be defined in different ways in clinical medicine, depending on the nature and purpose of the measurement. One approach is to obtain measurements from a large sample of randomly selected, asymptomatic subjects without known diseases associated with neuropathy, and to define values within the 95th, 97.5th, or 99th percentiles as normal. Another approach is to use parametric analyses to define the normal range statistically as values within two standard deviations of the mean. However, the latter method depends on a normal distribution. As noted by Robinson et al., ${ }^{28}$ few electrodiagnostic parameters follow a normal distribution. Hence, proper use of parametric analyses may require transformation of the raw data to approximate a more normal distribution.

Underlying all efforts to define normative values is the question of whether the sample is truly representative of the population for which the normal values will be used. Few studies of electrophysiological measurements meet this criterion, particularly for a worker population. This leads to reliance on normal values of uncertain statistical, clinical, or epidemiological relevance to workers. Our study attempts to address these concerns.

\section{METHODS}

Medical surveys were conducted among workers from seven work sites, representing a variety of manufacturing and office environments. The protocol included bilateral electrodiagnostic testing of distal sensory responses at the wrists, self-administered questionnaires, anthropometric measurements, and physical examination of the neck, shoulders, and upper extremities. Examiners were masked to data collected in other parts of the survey. Study participants provided written informed consent that had been previously approved by the institutional review board at the University of Michigan School of Public Health.

Except for Site 4, examinations were performed during normal work hours on company time by personnel from the University of Michigan. Workers were relieved of their job duties to allow for completion of the medical survey. At Site 4, workers were required to complete the study protocol before or after their normal work hours, and they were not paid. This resulted in a participation rate that was substantially lower among workers at Site 4 (45\%). All other sites had participation rates greater than $70 \%$, and most were greater than $80 \%$. Overall there were 1255 eligible workers, and 955 survey participants, resulting in a participation rate of $76 \%$, which mitigates problems with selection bias.

Electrodiagnostic testing included measurement of the antidromic sensory response from the median and ulnar nerves. Ring electrodes were placed on digits II and V, respectively, and antidromic stimulation was applied $14 \mathrm{~cm}$ proximally. Participants had midpalm temperatures recorded, and were warmed if the hand temperature was below $32.0^{\circ} \mathrm{C}$. All tests were performed by physicians certified in electrodiagnostic medicine (JWA, MBB, RAW) and/or registered electrodiagnostic technologists working under their supervision. No needle examination was performed.

Each participant completed a self-administered questionnaire that included demographics, education, cigarette usage, past medical history, current health status, a discomfort survey of the upper extremities, and a psychosocial section eliciting information about the work environment. The reliability of the questionnaire is generally good to excellent. ${ }^{10}$ Subjects were instructed to report symptoms involving the wrists, hands, or fingers if there had been problems in those areas on more than three separate episodes, or one episode had lasted more than 1 week in the 12 months preceding the study.

Anthropometric data collection included bilateral measurements of the index finger length and circumference, wrist width and depth, and right triceps skinfold thickness. In addition, weight and height were measured, and body mass index (BMI) $\left(\mathrm{kg} / \mathrm{m}^{2}\right)$ was calculated.

Exclusion criteria for determination of the normative cohort included: any symptoms in the wrists, hands, or fingers $(n=490)$; self-reported medical conditions diagnosed by a physician including carpal tunnel syndrome $(n=76)$, diabetes, excluding diabetes solely related to pregnancy $(n=27)$, gout $(n=$ $15)$, rheumatoid arthritis $(n=20)$, thoracic outlet syndrome $(n=3)$, thyroid dysfunction $(n=52)$, and ulnar neuropathy $(n=15)$; current pregnancy $(n=$ 8 ) ; hand temperatures less than $32^{\circ} \mathrm{C}$ despite warming $(n=43)$; and jobs characterized by highly repetitive work $(n=178) \cdot{ }^{16}$ A total of 629 subjects met one or more exclusion criteria.

Statistical Analysis. Statistical analyses were performed using Stata $^{\mathrm{TM}} 5.0$ for Windows. ${ }^{30}$ Summary statistics for the demographic and electrophysiologic variables were generated, and ordinary least squares 
regression models built. Quantile-normal graphs were produced for visual inspection, and tests for skewness and kurtosis performed to determine the source of nonnormality problems. Transformations were done based on Tukey's ladder of powers to correct for both skewed and kurtotic distributions.

Best fit equations were developed using linear regression, and standardized regression coefficients reported. Inclusion criteria were that the beta coefficient had a $P$ value less than 0.05 , or the partial $R^{2}$ associated with adding the variable was greater than 0.05 , and biological plausibility. Plots of residuals versus fitted values were checked for heteroscedasticity, as well as the Cook-Weisberg test for nonconstant variance. Correlation matrices were inspected for collinearity among the explanatory variables.

Prediction equations were fitted to forecast electrophysiologic outcomes of the mean sensory amplitudes, and onset and peak latencies for women and men, ages 20, 30, 40, and 50 years, with hand temperature of $33^{\circ} \mathrm{C}$ (the average "normal" temperature), based on selected parameter settings. Based on one-sided prediction intervals, the lower 95th percentiles for amplitudes, and upper 95th percentiles for latencies were also compiled.

\section{RESULTS}

After using the "normal" exclusion criteria, a cohort of 326 workers was identified without wrist, hand, or finger symptoms, certain medical history, hand temperatures less than $32^{\circ} \mathrm{C}$, or highly repetitive jobs. This cohort was $34 \%$ of all workers, and represented $30-44 \%$ of workers from each site.

The average age in the normative cohort was 36.2 years (range: 19-66 years). One hundred fifty-nine $(49 \%)$ of the workers were female. Mean BMI was $27.1 \mathrm{~kg} / \mathrm{m}^{2}$ for women, and $27.8 \mathrm{~kg} / \mathrm{m}^{2}$ for men. Right hand dominance was reported by 293 (90\%). Over half $(54 \%)$ had never smoked. There were no significant differences between the workers in the "normal" cohort and workers excluded from the " "normal" cohort in age, sex, hand dominance, and smoking status (data not shown). Mean BMI was also comparable for women and men between the two groups; however, the range was greater in the "normal" cohort.

Table 1 summarizes the NCS results for the normative cohort of 326 workers. The 5 th percentile of the median sensory amplitude in the dominant hand was $14.0 \mu \mathrm{V}$. The 95th percentile onset latency and peak latency were $3.2 \mathrm{~ms}$ and $4.0 \mathrm{~ms}$, respectively. The 95th percentile for the difference between median and ulnar sensory peak latencies was $0.8 \mathrm{~ms}$ in the dominant hand.

Appropriate transforms were identified for the electrophysiologic measures. These transforms involved inverses, inverse cubes, square roots, or logarithms of the original measures (see Table 2) to create acceptable distributions approximating normality. Ordinary least squares regression modeling with the transformed variables resulted in equations that indicated age, sex, hand temperature, and certain anthropometric factors were significant covariates (the regression models have fewer than 326 observations due to missing data for some covariates). Table 2 lists the standardized regression coefficients, illustrating the relative importance of the explanatory variables in each model. The signs of the coefficients are different from those typically expected due to the effect of the transforms.

\section{DISCUSSION}

Sampling. Most studies of normative values have made use of convenience or feasibility samples, composed of available hospital personnel, clinical colleagues, or students. 1,5,12,13,18,21,32 While convenient, and providing valuable information, this type of sample has limitations for generalizability. Many of

\begin{tabular}{|c|c|c|c|c|c|c|c|c|c|c|c|c|}
\hline \multirow[b]{2}{*}{ Parameter } & \multicolumn{6}{|c|}{ Dominant hand } & \multicolumn{6}{|c|}{ Nondominant hand } \\
\hline & $n$ & $\begin{array}{l}\text { Mean } \\
(\mathrm{SD})\end{array}$ & $\begin{array}{l}\text { Median } \\
\text { [Range] }\end{array}$ & $\begin{array}{l}\text { 90th } \\
\% \text {-ile }\end{array}$ & $\begin{array}{l}\text { 95th } \\
\% \text {-ile }\end{array}$ & $\begin{array}{l}\text { 99th } \\
\% \text {-ile }\end{array}$ & $n$ & $\begin{array}{l}\text { Mean } \\
(\mathrm{SD})\end{array}$ & $\begin{array}{l}\text { Median } \\
\text { [Range] }\end{array}$ & $\begin{array}{l}\text { 90th } \\
\% \text {-ile }\end{array}$ & $\begin{array}{l}\text { 95th } \\
\% \text {-ile }\end{array}$ & $\begin{array}{l}\text { 99th } \\
\% \text {-ile }\end{array}$ \\
\hline \multicolumn{13}{|l|}{ Median sensory (wrist) } \\
\hline Amplitude $(\mu \mathrm{V})^{\star}$ & 324 & $35.6(14.8)$ & 34.6 [5.5-83.3] & 18.0 & 14.0 & 7.0 & 324 & $39.6(17.2)$ & 38.0 [3.9-103.7] & 20.0 & 13.7 & 8.9 \\
\hline Onset latency (ms) & 324 & $2.5(0.3)$ & $2.5[2.0-4.8]$ & 3.0 & 3.2 & 3.7 & 324 & $2.5(0.3)$ & $2.4[1.7-4.6]$ & 2.9 & 3.1 & 3.5 \\
\hline Peak latency (ms) & 324 & $3.2(0.4)$ & $3.2[2.6-6.0]$ & 3.7 & 4.0 & 4.5 & 324 & $3.2(0.4)$ & $3.1[2.4-5.7]$ & 3.7 & 3.9 & 4.7 \\
\hline \multicolumn{13}{|l|}{ Ulnar sensory (wrist) } \\
\hline Amplitude $(\mu \mathrm{V})^{\star}$ & 324 & $33.6(16.2)$ & $30.4[4.0-102.7]$ & 16.6 & 12.5 & 5.9 & 323 & $35.7(17.2)$ & 32.0 [4.9-101.5] & 16.0 & 11.3 & 9.0 \\
\hline Onset latency (ms) & 324 & $2.4(0.2)$ & $2.4[1.8-3.5]$ & 2.7 & 2.8 & 3.2 & 323 & $2.5(0.2)$ & $2.4[1.8-3.7]$ & 2.8 & 2.8 & 3.1 \\
\hline Peak latency (ms) & 324 & $3.1(0.3)$ & $3.1[2.6-4.1]$ & 3.4 & 3.6 & 3.8 & 323 & $3.1(0.2)$ & $3.1[2.4-4.1]$ & 3.4 & 3.6 & 3.8 \\
\hline \multicolumn{13}{|l|}{ Median-ulnar peak } \\
\hline latency (ms) & 324 & $0.2(0.4)$ & $0.1[-0.8-2.6]$ & 0.5 & 0.8 & 1.5 & 323 & $0.1(0.3)$ & $0.0[-0.7-2.8]$ & 0.5 & 0.7 & 1.1 \\
\hline Hand temperature $\left({ }^{\circ} \mathrm{C}\right)^{\star}$ & 315 & $33.2(0.8)$ & $33.0[32.0-35.7]$ & 32.0 & 32.0 & 32.0 & 312 & $33.3(0.9)$ & $33.0[32.0-36.0]$ & 32.0 & 32.0 & 32.0 \\
\hline
\end{tabular}

*Note that percentiles are 'reversed' for amplitudes and hand temperature, and represent the 10th, 5th and 1st percentiles. 


\begin{tabular}{|c|c|c|c|c|c|c|c|c|c|c|c|c|}
\hline \multirow[b]{2}{*}{$\begin{array}{l}\text { Dependent } \\
\text { variable }^{\star}\end{array}$} & \multicolumn{11}{|c|}{ Standardized regression coefficients } & \multirow[b]{2}{*}{$R^{2}$} \\
\hline & Number & Constant & Age & Sext & $\begin{array}{c}\text { Hand } \\
\text { temperature }\end{array}$ & Weight & BMl & $\begin{array}{l}\text { Wrist } \\
\text { width }\end{array}$ & $\begin{array}{l}\text { Wrist } \\
\text { depth }\end{array}$ & $\begin{array}{l}\text { Finger } \\
\text { length }\end{array}$ & $\begin{array}{c}\text { Finger } \\
\text { circumference }\end{array}$ & \\
\hline \multicolumn{13}{|l|}{ Dominant hand } \\
\hline Median sensory amplitude & 323 & 11.64 & -0.3949 & 0.2445 & & & & & & & \multirow[t]{3}{*}{-0.3370} & 0.51 \\
\hline Median sensory onset latency & 313 & -0.1019 & -0.3283 & 0.2981 & 0.2320 & & -0.2076 & 0.3477 & -0.2752 & & & 0.27 \\
\hline Median sensory peak latency & 313 & -0.0699 & -0.3568 & 0.2691 & 0.3017 & -0.1901 & & 0.3093 & -0.1823 & & & 0.27 \\
\hline Ulnar sensory amplitude & 323 & 10.66 & -0.3464 & 0.3245 & & & & & & & \multirow{3}{*}{-0.2732} & 0.48 \\
\hline Ulnar sensory onset latency & 313 & -0.0036 & -0.2974 & 0.3407 & 0.2896 & & & 0.1551 & & -0.1855 & & 0.27 \\
\hline Ulnar sensory peak latency & 313 & -0.0309 & -0.3167 & 0.3032 & 0.3649 & & & 0.2127 & & -0.2620 & & 0.31 \\
\hline \multicolumn{12}{|l|}{$\begin{array}{l}\text { latency difference } \\
\text { Nondominant hand }\end{array}$} & 0.08 \\
\hline Median sensory amplitude & 323 & 10.90 & -0.3482 & 0.3322 & & & & & & & \multirow[t]{3}{*}{-0.2515} & 0.46 \\
\hline Median sensory onset latency & 311 & 0.0003 & -0.3089 & 0.3083 & 0.2074 & -0.2185 & & 0.2028 & & & & 0.21 \\
\hline Median sensory peak latency & 311 & -0.0580 & -0.3253 & 0.1929 & 0.3023 & -0.1093 & & & & & & 0.23 \\
\hline UInar sensory amplitude & 322 & 10.78 & -0.2825 & 0.3337 & & & & & & & \multirow[t]{3}{*}{-0.2860} & 0.45 \\
\hline Ulnar sensory onset latency & 310 & -0.0527 & -0.2812 & 0.3816 & 0.3287 & & & & & & & 0.31 \\
\hline latency difference & 323 & 0.1554 & & & & & 0.2342 & & & -0.1344 & & 0.07 \\
\hline
\end{tabular}

${ }^{\star}$ Transformations of dependent variables were as follows: amplitudes (square root), median onset and peak latencies in the dominant hand and median peak latency in the nondominant hand (inverse cube), ulnar onset and peak latencies and median sensory onset latency in the nondominant hand (inverse), median-ulnar peak latency differences $[\log ($ difference +1$)]$.

tMen $=0$, women $=1$. $\mathrm{P}$ values for $\mathrm{F}$ statistics in all models $<0.00005$

these studies were small, and thus lack adequate statistical power. Also, we suspect that many of the convenience samples have a spectrum bias, ${ }^{25}$ producing results of questionable validity for comparison with the general population or active workers.

In contrast to convenience samples, community sampling is a routine practice for determining "normal values" for biological parameters such as in spirometric testing. ${ }^{7,11}$ However, other than reports by Dyck et al. ${ }^{9}$ and Stetson et al., ${ }^{31}$ we are unaware of any well-designed epidemiological studies that have collected data from randomly selected asymptomatic, nondiseased community residents or workers, as has been done in the present study.

We focused exclusively on active workers to generate a large set of electrophysiologic parameters to assess normative values. The importance of selecting an appropriate reference cohort was emphasized by O'Brien and Dyck ${ }^{20}$ in their guide for setting normal values. As mentioned, the workers in the present study represented a wide variety of employment settings, including various manufacturing and office environments, enhancing the robustness of findings. This type of sample provided a unique opportunity to establish normative values, and strengthens the validity of the results for a worker population.

Explanatory Variables. As Kimura ${ }^{14}$ outlined in his review of nerve conduction techniques, several variables affect nerve conduction, including temperature, age, and the normal variation in nerve function. However, in our experience, laboratories typically establish cutoffs for normal ranges of nerve conduction measures without considering such fac- tors. In clinical practice, there is usually no quantitative adjustment for age, sex, anthropometry, or surface temperature. This practice continues despite mounting evidence that variables such as age and temperature ${ }^{6}$ need to be considered for accurate interpretation of results. Various studies ${ }^{9,15,19,22,24,31,33}$ have suggested that age, sex, BMI, wrist ratio, oral contraceptive use, oophorectomy, wrist dimension, weight, height, or certain medical conditions may contribute valuable information about nerve function. Normal values that are not corrected (for age, for instance) have been cited as inadequate reference values. ${ }^{2,20,27}$ The present study provides further evidence of the need to create an electrodiagnostic algorithm accounting for significant explanatory variables.

Our results suggest that adjusting sensory nerve conduction test results for relevant variables will improve the accuracy of interpretation. Age, sex, and hand temperature were significant covariates in our models of mean peak and onset latencies in both the median and ulnar nerves for dominant and nondominant hands. The most robust models were for sensory amplitudes both in the median and ulnar nerves for dominant and nondominant hands. Almost $50 \%$ of the variance in nerve function was explained by these models. The median-ulnar difference was found to be the least sensitive to age, sex, and temperature, suggesting it may be the best measure to use if covariates are not considered. Nonetheless, the overall accuracy of testing would improve by taking relevant variables into consideration. If one excludes the median-ulnar difference, our regression models explained between $21 \%$ and $51 \%$ of the variance. 
The models demonstrated remarkable internal consistency-age, sex, hand temperature, and certain anthropometric factors were significant in all models of onset and peak latencies. Similar to previous reports, ${ }^{17,31}$ amplitudes were affected by finger circumference. In addition, there was striking symmetry between the dominant and nondominant hands, with variables of similar significance and coefficients of similar magnitude. Except for ulnar onset and peak latencies, models for the dominant hand explained slightly more variance. Smoking (expressed as pack years or ever/never smoked) had no significant association with amplitude or latency measures. Letz and Gerr ${ }^{17}$ found negative associations between current smoking status and amplitudes, but no significant association with median or ulnar sensory nerve conduction velocity.

We checked the robustness of the models of examining alternate explanatory variables. For example, substituting BMI for weight resulted in less than a $2 \%$ reduction in $R^{2}$ in the model for median sensory peak latencies of the dominant hand. Alternately, wrist width and depth could be exchanged for the ratio of width to depth without substantial difference in explanatory power. Substitution of alternate covariates may be more practical, since some of the covariates used (e.g., finger circumference) are not routinely collected from patients in clinical settings.

These findings are consistent with prior studies that have shown age and anthropometry as significant covariates of peripheral nerve function. Letz and Gerr $^{17}$ reported skin temperature, height, BMI, age, race, and smoking status as important covariates in median and ulnar sensory amplitude models. Stetson et al. ${ }^{31}$ reported age, height, and finger circumference as significant factors in median and ulnar sensory amplitudes; age, height, and wrist ratio for median sensory latency; and age and height as important for ulnar sensory latency.

One curious finding is that even though nerve function was measured using the 5 th digit for the ulnar nerves, the length of the 2nd digit was significant in the ulnar peak latency regression models. Although the length of the 5th digit was not measured, we suspect that there is good correlation between the lengths of digits 2 and 5, and that the length of digit 2 serves as a surrogate for the length of digit 5 in such models.

The prediction intervals for the median sensory amplitude showed a decreasing trend with age and finger circumference (Table 3). The onset and peak latency predictions increased with age and BMI or weight (e.g., median peak latencies increased ap- proximately $20 \%$ between ages 20 and 50 years). Women had larger amplitudes than men, even after adjusting for finger circumference. Of particular importance, the magnitude of the variance increased with age and anthropometric factors in all models (i.e., not only did the mean of the predicted value increase, the distance between the mean and upper bound increased as well).

This study challenges the conventional cutoff criteria for making the diagnosis of a median mononeuropathy. Absolute cutoffs as well as relative cutoffs between median and ulnar latencies have been published in previous studies, ${ }^{12,29}$ with most suggesting a peak median sensory latency of 3.5-3.8 ms. In our group of 324 workers, we found $4.0 \mathrm{~ms}$ was the upper 95th percentile in the dominant hand. Based on our prediction equation that accounted for age, sex, and weight, the upper 95th percentile for the dominant hand ranged from 3.3 to $5.2 \mathrm{~ms}$.

The standard relative median to ulnar comparison is 0.4 to $0.5 \mathrm{~ms}$. This is reported to avoid false positive findings, ${ }^{26}$ but our data suggest a cutoff of $0.8 \mathrm{~ms}$ as the upper limit of normal in the dominant hand of active workers. Use of this new diagnostic criterion would make a significant impact on the clinical management of cases. With the conventional cutoff criteria, many cases of CTS may be "confirmed" in individuals who are electrically normal.

Given that the reference values are valid, the question remains as to whether the measures are reliable. Letz and Gerr $^{17}$ reported highly significant variability between examiners in their work with over 4000 subjects. They noted that with such a large sample size, even trivial differences could appear statistically significant, even though the findings might be of little clinical consequence. Chaudhry et al. ${ }^{3,4}$ also have addressed this concern in two reportsone of 7 healthy subjects and another with 6 patients with diabetic neuropathy. In both studies, they found a high degree of intraexaminer reliability; however, significant interexaminer differences were found, although both studies were very small. Our studies are subject to this variability as well, and we intend to evaluate the reliability issue more directly via repeated nerve conduction studies with multiple examiners

Due to the large number of electrophysiological tests, it may not be practical to standardize all tests. However, more commonly used tests could be standardized by studying large numbers of properly selected control subjects. An approach similar to that used with spirometry testing would improve the validity of interpretation of electrophysiological outcomes and the accuracy of CTS and other diagnoses. 


\begin{tabular}{|c|c|c|c|c|c|c|c|c|c|c|}
\hline \multirow[b]{2}{*}{$\begin{array}{l}\text { Age } \\
\text { (years) }\end{array}$} & \multirow[b]{2}{*}{ Sex } & \multicolumn{3}{|c|}{ Median sensory amplitude } & \multicolumn{3}{|c|}{ Median sensory onset latency } & \multicolumn{3}{|c|}{ Median sensory peak latency } \\
\hline & & $\begin{array}{c}\text { Dominant finger } \\
\text { circumference } \\
(\mathrm{mm})\end{array}$ & $\begin{array}{l}\text { Predicted } \\
\text { mean } \\
\text { value }(\mu \mathrm{V})\end{array}$ & $\begin{array}{c}\text { 95th percentile- } \\
\text { lower bound } \\
(\mu \mathrm{V})\end{array}$ & $\begin{array}{c}\text { BMI } \\
\left(\mathrm{kg} / \mathrm{m}^{2}\right)\end{array}$ & $\begin{array}{l}\text { Predicted } \\
\text { mean } \\
\text { value }(\mathrm{ms})\end{array}$ & $\begin{array}{l}\text { 95th Percentile- } \\
\text { upper bound (ms) }\end{array}$ & $\begin{array}{l}\text { Weight } \\
(\mathrm{kg})\end{array}$ & $\begin{array}{l}\text { Predicted } \\
\text { mean } \\
\text { value (ms) }\end{array}$ & $\begin{array}{l}\text { 95th percentile- } \\
\text { upper bound (ms) }\end{array}$ \\
\hline 20 & Female & 55 & 61.0 & 39.8 & 23 & 2.3 & 2.6 & 50 & 2.9 & 3.3 \\
\hline 20 & Female & 63 & 53.4 & 33.7 & 28 & 2.3 & 2.7 & 80 & 3.0 & 3.4 \\
\hline 20 & Female & 71 & 46.3 & 28.1 & 32 & 2.3 & 2.8 & 110 & 3.1 & 3.6 \\
\hline 20 & Female & 79 & 39.7 & 22.8 & 37 & 2.4 & 2.8 & 140 & 3.2 & 3.8 \\
\hline 30 & Female & 55 & 53.4 & 33.8 & 23 & 2.4 & 2.8 & 50 & 3.0 & 3.5 \\
\hline 30 & Female & 63 & 46.3 & 28.2 & 28 & 2.4 & 2.8 & 80 & 3.1 & 3.6 \\
\hline 30 & Female & 71 & 39.7 & 23.1 & 32 & 2.4 & 2.9 & 110 & 3.2 & 3.8 \\
\hline 30 & Female & 79 & 33.6 & 18.3 & 37 & 2.5 & 3.0 & 140 & 3.2 & 4.0 \\
\hline 40 & Female & 55 & 46.4 & 28.2 & 23 & 2.4 & 2.9 & 50 & 3.1 & 3.6 \\
\hline 40 & Female & 63 & 39.8 & 23.2 & 28 & 2.5 & 3.0 & 80 & 3.2 & 3.8 \\
\hline 40 & Female & 71 & 33.7 & 18.5 & 32 & 2.5 & 3.1 & 110 & 3.3 & 4.0 \\
\hline 40 & Female & 79 & 28.1 & 14.3 & 37 & 2.6 & 3.2 & 140 & 3.2 & 4.3 \\
\hline 50 & Female & 63 & 33.7 & 18.6 & 28 & 2.6 & 3.2 & 80 & 3.3 & 4.0 \\
\hline 50 & Female & 71 & 28.1 & 14.5 & 32 & 2.6 & 3.3 & 110 & 3.4 & 4.3 \\
\hline 50 & Female & 79 & 23.0 & 10.8 & 37 & 2.7 & 3.5 & 140 & 3.5 & 4.7 \\
\hline 20 & Male & 55 & 51.6 & 32.0 & 23 & 2.4 & 2.8 & 50 & 3.0 & 3.5 \\
\hline 20 & Male & 63 & 44.6 & 26.8 & 28 & 2.4 & 2.9 & 80 & 3.1 & 3.6 \\
\hline 20 & Male & 71 & 38.2 & 21.9 & 32 & 2.4 & 3.0 & 110 & 3.2 & 3.7 \\
\hline 20 & Male & 79 & 32.2 & 17.4 & 37 & 2.5 & 3.1 & 140 & 3.2 & 4.0 \\
\hline 30 & Male & 55 & 44.7 & 26.6 & 23 & 2.4 & 3.0 & 50 & 3.1 & 3.6 \\
\hline 30 & Male & 63 & 38.2 & 21.9 & 28 & 2.5 & 3.1 & 80 & 3.2 & 3.8 \\
\hline 30 & Male & 71 & 32.2 & 17.5 & 32 & 2.5 & 3.1 & 110 & 3.3 & 4.0 \\
\hline 30 & Male & 79 & 26.8 & 13.5 & 37 & 2.6 & 3.3 & 140 & 3.4 & 4.2 \\
\hline 40 & Male & 55 & 38.2 & 21.7 & 23 & 2.5 & 3.2 & 50 & 3.2 & 3.8 \\
\hline 40 & Male & 63 & 32.3 & 17.4 & 28 & 2.6 & 3.3 & 80 & 3.3 & 4.0 \\
\hline 40 & Male & 71 & 26.8 & 13.6 & 32 & 2.6 & 3.4 & 110 & 3.4 & 4.3 \\
\hline 40 & Male & 79 & 21.8 & 10.1 & 37 & 2.7 & 3.6 & 140 & 3.5 & 4.6 \\
\hline 50 & Male & 55 & 32.3 & 17.2 & 23 & 2.6 & 3.4 & 50 & 3.3 & 4.1 \\
\hline 50 & Male & 63 & 26.8 & 13.5 & 28 & 2.7 & 3.6 & 80 & 3.4 & 4.3 \\
\hline 50 & Male & 71 & 21.9 & 10.1 & 32 & 2.7 & 3.8 & 110 & 3.5 & 4.7 \\
\hline
\end{tabular}

Predicted values were calculated from regression equations based on dominant hand temperature of $33^{\circ} \mathrm{C}$; wrist width of $52 \mathrm{~mm}$ in females, $59 \mathrm{~mm}$ in males; and wrist depth of $37 \mathrm{~mm}$ in females, $41 \mathrm{~mm}$ in males, when indicated.

Computer technology now allows for immediate display of raw and predicted measurements with confidence intervals to interpret results. This could be done with adjustment for the previously mentioned variables in multiple regression models, despite the underlying complexity of variable transformation, as is current standard practice in pulmonary laboratories.

It is apparent from this study that fixed absolute thresholds without adjustment for age, sex, temperature, or anthropometric factors may result in many false positive (and false negative) results. Even with control of temperature within an acceptable range, hand temperature was still an important covariate of latency. Measurement of anthropometric variables and strict control for temperature (e.g., warming of cool limbs) are essential for more valid interpretation of nerve conduction outcomes. Even with these adjustments, however, current standards for diagnosing CTS among workers appear too sensitive, and need fine-tuning to avoid misclassification of results that are within a normal reference range.

Conclusion. There are a number of strengths in this study, most notably: 1) the composition of the sample; 2) the use of rigorous exclusion criteria to select healthy subjects; and 3) the sample size. The sample, consisting of workers from various industrial and office settings, provided a valid reference for normative values of workers. Without being too strict, the criteria used to select subjects for the normative analyses provided a reasonable definition of normal. Unmeasured factors related to increased risk of peripheral neuropathy, such as solvent exposure or use of neurotoxic medications (e.g., certain antineoplastic agents), were unlikely confounders at the study sites or among active workers. The generally high rate of worker participation and the large sample further strengthen the validity of the normative values.

Additional studies are needed involving large numbers of randomly selected, asymptomatic subjects from worker populations without known diseases associated with neuropathy to further validate electrophysiological models and to determine appropriate covariates for a computer-based algorithm. The normative values presented in this study should 
provide better precision in estimating nerve function in the working population. It is clear that improving the body of normative data provides the means for a more accurate interpretation of "normal" nerve conduction studies among workers.

The purpose of this study was to evaluate nerve conduction data among asymptomatic, healthy workers to assess what is considered "normal." The current diagnostic methods of using fixed thresholds without adjustment for age and sex are not appropriate for a worker population, and could result in substantial misclassification. Age, sex, and hand temperature were the most important variables in our electrophysiologic models. Weight, BMI, wrist width, wrist depth, finger length, and finger circumference also had significant explanatory power. The models presented illustrate the importance of considering covariates such as age, sex, hand temperature, and anthropometric factors when interpreting nerve conduction studies.

Presented, in part, at the International Conference on Occupational Disorders of the Upper Extremities, Ann Arbor, Michigan, October 24-25, 1996.

The data for these analyses were collected in studies supported by governmental agencies and private industry. We express our appreciation to the workers and managers who participated in the studies, and thank the Office Ergonomics Research Committee for supporting the work presented here. We also thank M. Anthony Schork, PhD, for his expert guidance in the biostatistical analyses.

\section{REFERENCES}

1. Buchthal F, Rosenfalck A: Sensory conduction from digit to palm and from palm to wrist in the carpal tunnel syndrome. J Neurol Neurosurg Psychiatry 1971;34:243-252.

2. Campbell WW, Robinson LR: Deriving reference values in electrodiagnostic medicine. Muscle Nerve 1993;16:424-428.

3. Chaudhry V, Cornblath DR, Mellits ED, Avila O, Freimer ML, Glass JD, Reim J, Ronnett GV, Quaskey SA, Kuncl RW: Inter- and intra-examiner reliability of nerve conduction measurements in normal subjects. Ann Neurol 1991;30:841843.

4. Chaudhry V, Corse AM, Freimer ML, Glass JD, Mellits ED, Kuncl RW, Quaskey SA, Cornblath DR: Inter- and intraexaminer reliability of nerve conduction measurements in patients with diabetic neuropathy. Neurology 1994;44:1459-1462.

5. Dawson GD, Scott JW: The recording of nerve action potentials through skin in man. J Neurol Neurosurg Psychiatry 1949;12:259-267.

6. Denys EH: AAEM Minimonograph \#14: The influence of temperature in clinical neurophysiology. Muscle Nerve 1991;14:795-811.

7. Dockery DW, Ware JH, Ferris BG, Glicksberg DS, Fay ME, Spiro A III, Speizer FE: Distribution of forced expiratory volume in one second and forced vital capacity in healthy, white, adult never-smokers in six US cities. Am Rev Respir Dis 1985;131:511-520.

8. Dorfman LJ, Robinson LR: AAEM Minimonograph \#47: Normative data in electrodiagnostic medicine. Muscle Nerve 1997;20:4-14.

9. Dyck PJ, Litchy SJ, Lehman KA, Hokanson BA, Low PA,
O'Brien PC: Variables influencing neuropathic endpoints: the Rochester Diabetic Neuropathy Study of Healthy Subjects. Neurology 1995;45:1115-1121.

10. Franzblau A, Salerno DF, Armstrong TJ, Werner RA: Testretest reliability of an upper extremity discomfort questionnaire in an industrial population. Scand J Work Environ Health 1997;23:299-307.

11. Glindmeyer HW, Lefante JJ, McColloster C, Jones RN, Weill $\mathrm{H}$ : Blue-collar normative spirometric values for Caucasian and African-American men and women aged 18 to 65. Am J Respir Crit Care Med 1995;151:412-422.

12. Jackson DA, Clifford JC: Electrodiagnosis of mild carpal tunnel syndrome. Arch Phys Med Rehabil 1989;70:199-204.

13. Johnson EW, Melvin JL: Sensory conduction studies of the median and ulnar nerves. Arch Phys Med Rehabil 1967;48:25-38.

14. Kimura J: Principles and pitfalls of nerve conduction studies. Ann Neurol 1984;16:415-429.

15. Kraft GH, Halvorson GA: Median nerve residual latency: normal value and use in diagnosis of carpal tunnel syndrome. Arch Phys Med Rehabil 1983;64:221-226.

16. Latko WA, Armstrong TJ, Foulke JA, Herrin GD, Rabourn RA, Ulin SS: Development and evaluation of an observational method for assessing repetition in hand tasks. Am Ind Hyg Assoc J 1997;58:278-285.

17. Letz R, Gerr F: Covariates of human peripheral nerve function: 1. Nerve conduction velocity and amplitude. Neurotoxicol Teratol 1994;16:95-104.

18. Melvin JL, Harris DH, Johnson EW: Sensory and motor conduction velocities in the ulnar and median nerves. Arch Phys Med Rehabil 1966;47:511-519.

19. Nathan PA, Meadows KD, Doyle LS: Relationship of age and sex to sensory conduction of the median nerve at the carpal tunnel and association of slowed conduction with symptoms. Muscle Nerve 1988;11:1149-1153.

20. O'Brien PC, Dyck PJ: Procedures for setting normal values. Neurology 1995;45:17-23.

21. Padua L, Monaco ML, Valente EM, Tonali PA: A useful electrophysiologic parameter for diagnosis of carpal tunnel syndrome. Muscle Nerve 1996;19:48-53.

22. Radecki P: A gender specific wrist ratio and the likelihood of a median nerve abnormality at the carpal tunnel. Am J Phys Med Rehabil 1994;73:157-162.

23. Radecki P: Variability in the median and ulnar nerve latencies: implications for diagnosing entrapment. J Environ Med 1995;37:1293-1299.

24. Radecki P: Personal factors and blood volume movement in causation of median neuropathy at the carpal tunnel: a commentary. Am J Phys Med Rehabil 1996;75:235-238.

25. Ransohoff DF, Feinstein AR: Problems of spectrum and bias in evaluating the efficacy of diagnostic tests. $N$ Engl J Med 1978;299:926-930.

26. Redmond MD, Rivner MH: False positive electrodiagnostic tests in carpal tunnel syndrome. Muscle Nerve 1988;11:511-517.

27. Rivner MH, Swift TR, Crout BO, Rhodes KP: Toward more rational nerve conduction interpretations: the effect of height. Muscle Nerve 1990;13:232-239.

28. Robinson LR, Temkin NR, Fujimoto WY, Stolov WC: Effect of statistical methodology on normal limits in nerve conduction studies. Muscle Nerve 1991;14:1084-1090.

29. Ross MA, Kimura J: AAEM Case report \#2: The carpal tunnel syndrome. Muscle Nerve 1995;18:567-573.

30. StataCorp: Stata Statistical Software: Release 5.0 College Station, TX, Stata Corporation, 1997.

31. Stetson DS, Albers JW, Silverstein BA, Wolfe RA: Effects of age, sex and anthropometric factors on nerve conduction measures. Muscle Nerve 1992;15:1095-1104.

32. Thomas JE, Lambert EH, Cseuz KA: Electrodiagnostic aspects of carpal tunnel syndrome. Arch Neurol 1967;16:635-641.

33. Werner RA, Albers JW, Franzblau A, Armstrong TJ: The relationship between body mass index and the diagnosis of carpal tunnel syndrome. Muscle Nerve 1994;17:632-663. 